Article

\title{
Spiropyran-Isoquinoline Dyad as a Dual Chemosensor for Co(II) and In(III) Detection
}

\author{
Yong-Min Kho and Eun Ju Shin * \\ Department of Chemistry, Sunchon National University, Suncheon, Jeonnam 57922, Korea; melon414@scnu.ac.kr \\ * Correspondence: ejs@scnu.ac.kr; Tel.: +82-61-750-3635
}

Received: 4 August 2017; Accepted: 10 September 2017; Published: 19 September 2017

\begin{abstract}
Spiropyran derivatives have been studied as light-regulated chemosensors for a variety of metal cations and anions, but there is little research on chemosensors that simultaneously detect multiple metal cations. In this study, a spiropyran derivative with isoquinoline, SP-IQ, was prepared and it functions investigated as a light-regulated sensor for both $\mathrm{Co}^{2+}$ and $\mathrm{In}^{3+}$ cations. A colorless nonfluorescent SP-IQ converts to a pink-colored fluorescent MC-IQ by UV irradiation or standing in the dark, and MC-IQ returns to SP-IQ with visible light. Upon UV irradiation with the $\mathrm{Co}^{2+}$ cation for $7 \mathrm{~min}$, the stronger absorption at $540 \mathrm{~nm}$ and the similar fluorescence intensity at $640 \mathrm{~nm}$ are observed, compared to when no metal cation is added, due to the formation of a $\mathrm{Co}^{2+}$ complex with pink color and pink fluorescence. When placed in the dark with the $\mathrm{In}^{3+}$ cation for $7 \mathrm{~h}$, the colorless solution of SP-IQ changes to the $\operatorname{In}^{3+}$ complex with yellow color and pink fluorescence, which shows strong absorption at $410 \mathrm{~nm}$ and strong fluorescence at $640 \mathrm{~nm}$. Selective detection of the $\mathrm{Co}^{2+}$ cation with UV irradiation and the $\mathrm{In}^{3+}$ cation in the dark could be possible with SP-IQ by both absorption and fluorescence spectroscopy or by the naked eye.
\end{abstract}

Keywords: spiropyran; isoquinoline; chemosensor; cobalt; indium

\section{Introduction}

Cobalt salts have been used as pigments since ancient times to produce brilliant blue colors in paint, porcelain, and glass [1,2]. Cobalt alloys are used in powerful magnets, jet turbines, and medical orthopedic implants of the hip and knee because of its high-temperature strength, and corrosion and wear resistance. Radioactive cobalt-60 is used to treat cancer in radiotherapy. Cobalt is an essential trace element as a component of vitamin $\mathrm{B}_{12}$. However, cobalt is carcinogenic and causes heart and lung problems, occupational asthma, and vision and hearing problems, including tinnitus, deafness, and blindness [3].

Indium is notably used in the semiconductor industry to make indium tin oxide (ITO) for transparent conductive coatings on glass, which is an important part of touch screens, flat-screen TVs, and solar panels $[4,5]$. Indium metal is used as a light filter in low-pressure sodium vapor lamps, and as a mirror finish on windows of tall of an embryo to be teratogenic [6].

Numerous chemosensors have been buildings. Indium compounds are highly toxic and damage the heart, kidney, and liver, and causes the development developed for sensing various metal cations and anions. Among those, the detection techniques based on the change of color and/or fluorescence provide simple and inexpensive tools $[7,8]$. Therefore, colorimetric and/or fluorescent chemosensors for the detection of toxic heavy metals, such as $\mathrm{Co}^{2+}$ and $\mathrm{In}^{3+}$, have attracted significant interest because of their potential application in chemical, biological, industrial, and environmental research.

Organic photochromic materials have received great attention in various applications, including light-tunable biological and chemical systems, molecular logic gates, and light-regulated chemosensors [9]. Photochromic materials change their color reversibly through structural changes depending on whether they are exposed to UV light. 
Spiropyran derivatives have been extensively studied as typical photochromic molecules, which accomplish the reversible interconversion between colorless non-fluorescent spiropyran and colored fluorescent merocyanine (Scheme 1) [10]. Upon UV irradiation, a ring-closed spiropyran form is converted into a ring-opened merocyanine form by heterolytic cleavage of the spiro C-O bond [11]. Merocyanine is a resonance hybrid between a zwitterion form MCa and a neutral quinonoid form $\mathbf{M C b}[12,13]$. The merocyanine form is returned to the spiropyran form by ring-closure when exposed to visible light or thermal energy.

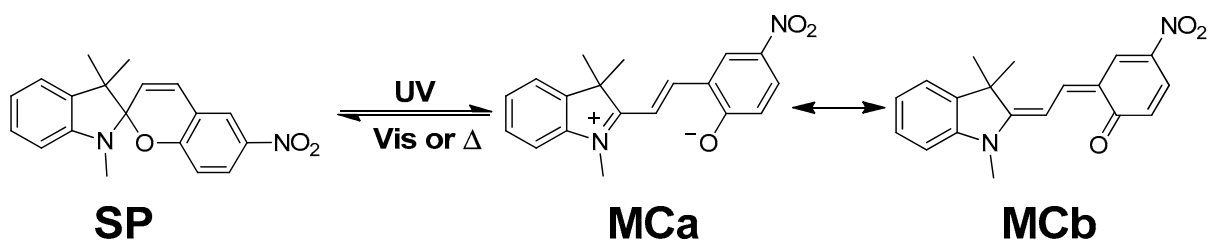

Scheme 1. Interconversion between spiropyran (SP) and merocyanine (MC). MC is a resonance hybrid between $\mathbf{M C a}$ and $\mathbf{M C b}$.

A negatively-charged phenolic oxygen in the ring-opened merocyanine form provides a chelating site for a variety of metal cations [14]. Spiropyran derivatives appended with a suitable ligand, which provides a cooperative binding site along with negatively-charged phenolic oxygen, can lead to light-regulated sensors for metal cations [15]. A variety of spiropyran-based chemosensors has been investigated as a selective, sensitive, and reproducible detection system for various metal cations [13-18].

Although chemosensors for a specific metal cation have been extensively developed, there are few studies on chemosensors that simultaneously detect multiple analytes [19-21].

In this paper, we report that SP-IQ, a spiropyran derivative appended with isoquinoline, functions as a light-regulated sensor for both $\mathrm{Co}^{2+}$ and $\mathrm{In}^{3+}$ cations.

\section{Results and Discussion}

\subsection{Interconversion between $S P-I Q$ and $M C-I Q$}

SP-IQ is colorless and non-fluorescent. It shows absorption maxima at 272 and $325 \mathrm{~nm}$ in $\mathrm{CH}_{3} \mathrm{CN} / \mathrm{H}_{2} \mathrm{O}(1 / 1, v / v)$.

Irradiation of SP-IQ using $350 \mathrm{~nm}$ light changed the colorless solution to MC-IQ of pink color. Absorption and fluorescence spectral changes of SP-IQ in $\mathrm{CH}_{3} \mathrm{CN} / \mathrm{H}_{2} \mathrm{O}(1 / 1, v / v)$ with the irradiation at $350 \mathrm{~nm}$ are shown in Figure 1. Due to the photoinduced conversion by $\mathrm{C}-\mathrm{O}$ bond cleavage from SP-IQ, a spiropyran form, to MC-IQ, a merocyanine form, new absorption at $540 \mathrm{~nm}$ and new fluorescence at $640 \mathrm{~nm}$ increase with irradiation time.

Figure 2 shows the spectral changes of absorption and fluorescence by the reverse reaction from MC-IQ (formed after irradiation of SP-IQ with $350 \mathrm{~nm}$ light for $7 \mathrm{~min}$ ) to SP-IQ over time (0-28 $\mathrm{min})$ under room illumination. When placed under room light, the pink color of MC-IQ is blurred. As MC-IQ reverts to SP-IQ through a ring closure reaction by visible light, the absorbance at $540 \mathrm{~nm}$ and the fluorescence intensity at $640 \mathrm{~nm}$ decrease. 

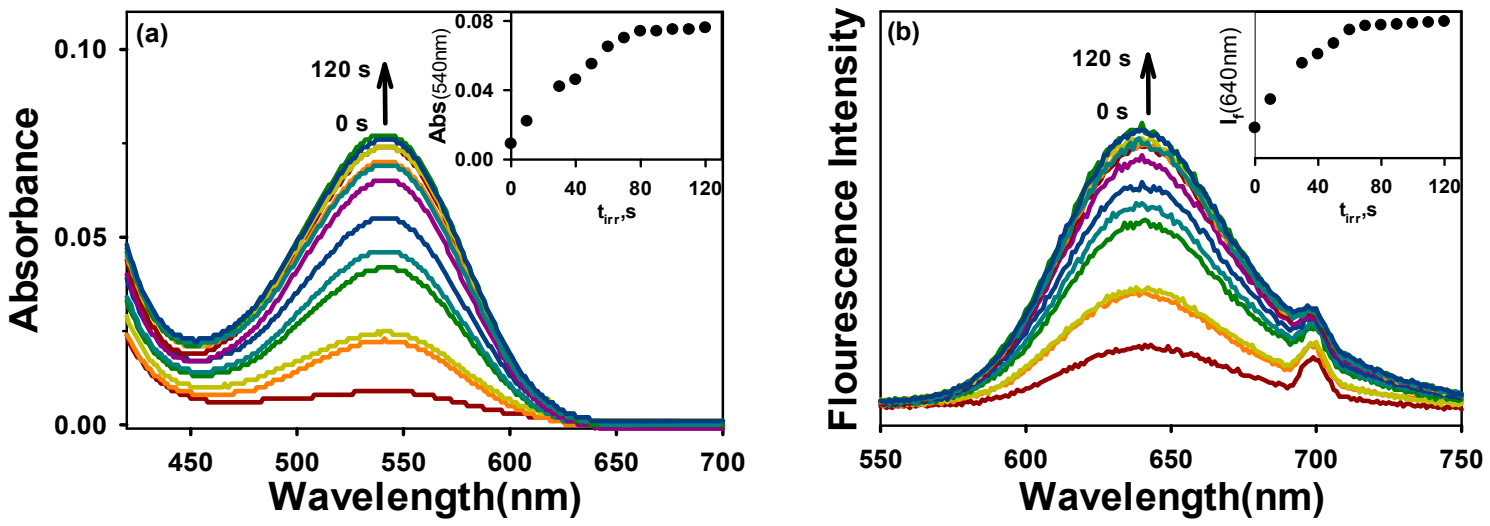

Figure 1. (a) Absorption and (b) fluorescence spectral changes of SP-IQ with irradiation time (0-120 s, Different color lines represent different irradiation times.) with UV irradiation at $350 \mathrm{~nm}$. Inset: Plots of (a) absorbance at $540 \mathrm{~nm}$ and (b) fluorescence intensity at $640 \mathrm{~nm}$ vs. irradiation time.
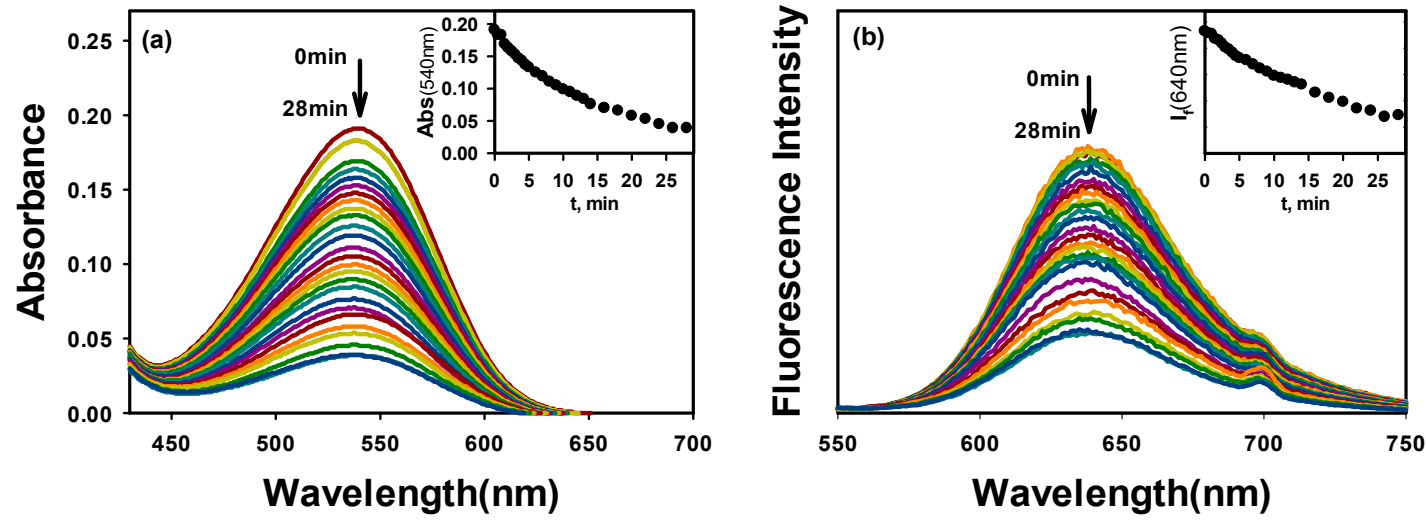

Figure 2. (a) Absorption and (b) fluorescence spectral changes by reverse reaction from MC-IQ (formed after irradiation of SP-IQ with $350 \mathrm{~nm}$ light for $7 \mathrm{~min}$ ) to SP-IQ over time (0-28 $\mathrm{min}$, Different color lines represent different irradiation times.) under room illumination. Inset: Plots of (a) absorbance at $540 \mathrm{~nm}$ and (b) fluorescence intensity at $640 \mathrm{~nm}$ vs. room illumination time.

The absorption and fluorescence spectral changes of SP-IQ which is placed in the dark (Figure 3) are very similar to those of SP-IQ which is irradiated at $350 \mathrm{~nm}$. The new absorption at $540 \mathrm{~nm}$ and the new fluorescence at $640 \mathrm{~nm}$ slowly increase over $6 \mathrm{~h}$ when the solution of SP-IQ is placed in the dark. The ring-opening reaction from SP-IQ to MC-IQ is thought to occur not only on UV irradiation, but also in the dark. Probably, the major isomer in UV light or darkness is MC-IQ, whereas the major isomer under visible light is SP-IQ.

Figure 4 shows the spectral changes of absorption and fluorescence by reverse reaction from MC-IQ (formed after dark incubation of SP-IQ for $7 \mathrm{~h}$ ) to SP-IQ with time (0-11 min) under room illumination. When placed in a lit room, the absorbance at $540 \mathrm{~nm}$ and the fluorescence intensity at $640 \mathrm{~nm}$ decrease, indicating that MC-IQ returns to SP-IQ through the ring closure reaction by visible light. 

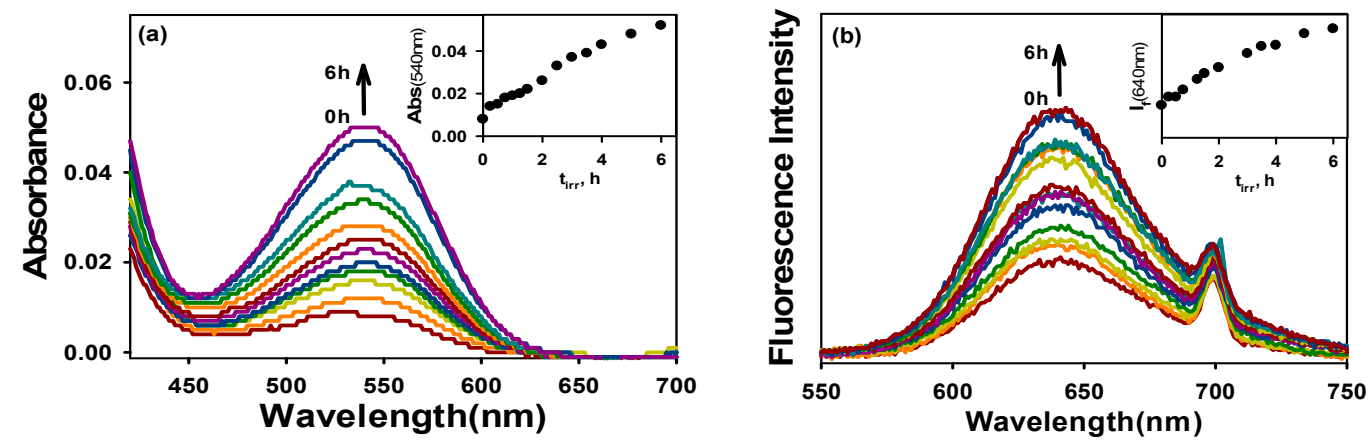

Figure 3. (a) Absorption and (b) fluorescence spectral changes of SP-IQ over time (0-6 h, Different color lines represent different times.) during the dark incubation. Inset: Plots of (a) absorbance at $540 \mathrm{~nm}$ and (b) fluorescence intensity at $640 \mathrm{~nm}$ vs. irradiation time.
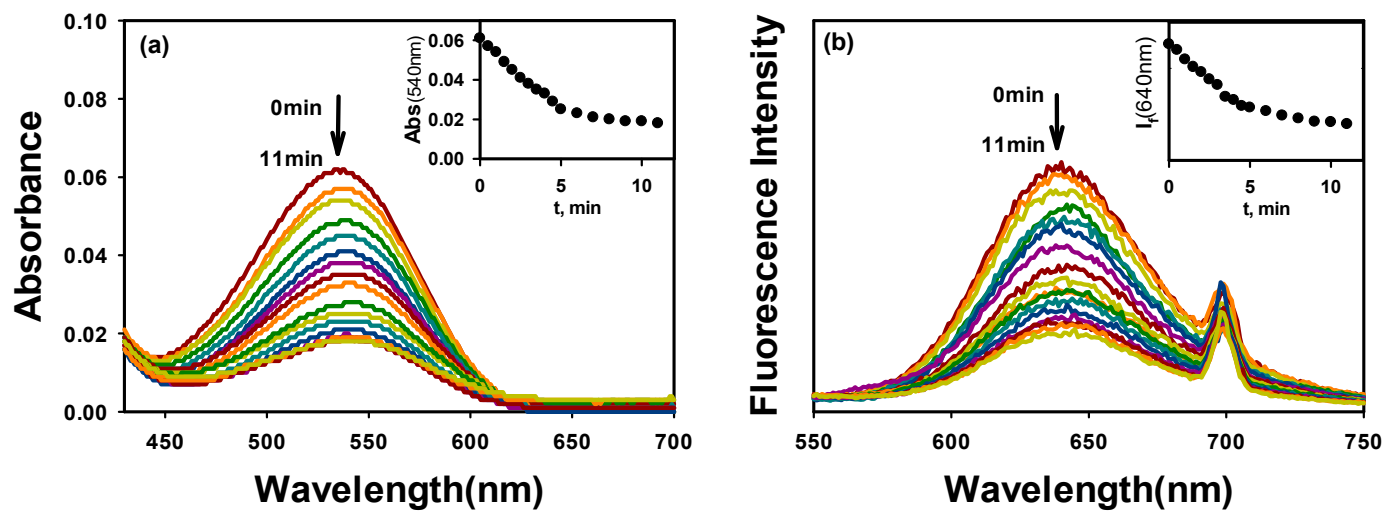

Figure 4. (a) Absorption and (b) fluorescence spectral changes by reverse reaction from MC-IQ (formed after dark incubation of SP-IQ for $7 \mathrm{~h}$ ) to SP-IQ with time (0-11 min, Different color lines represent different times.) under room illumination. Inset: Plots of (a) absorbance at $540 \mathrm{~nm}$ and (b) fluorescence intensity at $640 \mathrm{~nm}$ vs. room illumination time.

Most spiropyran derivatives convert from the spiropyran form to the merocyanine form by UV irradiation. Conversely, merocyanine converts to spiropyran by visible light, or thermally [10]. However, a colorless nonfluorescent SP-IQ converts to a pink-colored fluorescent MC-IQ by UV irradiation or in the dark, and MC-IQ returns to SP-IQ by visible light (Scheme 2). Regardless of whether MC-IQ is formed by UV irradiation or in the dark, MC-IQ returns to SP-IQ under room illumination, i.e., visible light. These observations are unusual and interesting. It is thought that while SP-IQ is the preferred isomer under visible light, MC-IQ is the preferred isomer in UV light or in the dark.

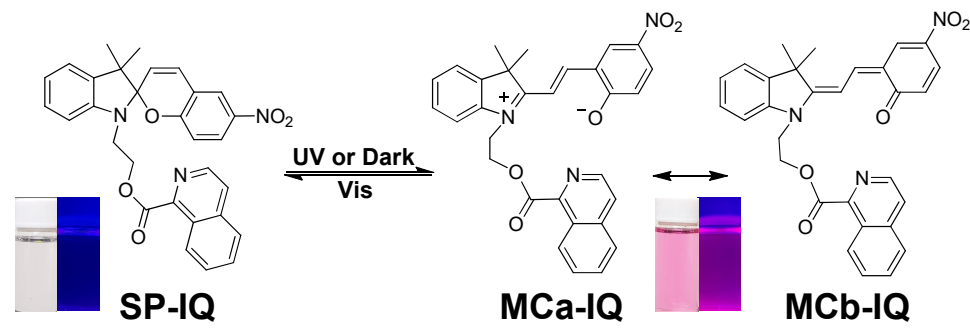

Scheme 2. Interconversion between SP-IQ and MC-IQ. MC-IQ is a resonance hybrid between MCa-IQ and MCb-IQ. In each pair of photos, left and right show the color and fluorescence of the solution, respectively. 


\subsection{Selective Sensing of $\mathrm{Co}^{2+}$}

Absorption and fluorescence spectra of SP-IQ show no changes with adding various metal cations $\left(\mathrm{Ag}^{2+}, \mathrm{Al}^{3+}, \mathrm{Cd}^{2+}, \mathrm{Co}^{2+}, \mathrm{Cu}^{2+}, \mathrm{Cu}^{+}, \mathrm{Fe}^{2+}, \mathrm{Hg}^{2+}, \mathrm{In}^{3+}, \mathrm{Ni}^{2+}, \mathrm{Zn}^{2+}\right)$.

However, upon UV irradiation, some changes for the absorption and fluorescence spectra of SP-IQ are observed with the addition of various metal cations. Figure 5 shows the absorption and fluorescence spectra, and the visual color and fluorescence of SP-IQ after $350 \mathrm{~nm}$ UV irradiation for 7 min with the addition of various metal cations. Figure $5 a$,b show that an absorption band at $540 \mathrm{~nm}$ and a fluorescence band at $640 \mathrm{~nm}$ appear after UV irradiation of SP-IQ without metal cations. UV irradiation with the $\mathrm{Co}^{2+}$ cation exhibits a high absorbance at 540 and a similar fluorescence intensity at $640 \mathrm{~nm}$, compared to the absence of metal cations. In the presence of metal cations other than $\mathrm{Co}^{2+}$ cation, the absorption at $540 \mathrm{~nm}$ and the fluorescence at $640 \mathrm{~nm}$ become weaker. Figure $5 \mathrm{c}$ shows pink solutions with no metal cation and with the addition of $\mathrm{Co}^{2+}$ cation. Colorless and nonfluorescent SP-IQ converts to pink MC-IQ after UV irradiation without metal cations. After UV irradiation with the addition of the $\mathrm{Co}^{2+}$ cation, the solution shows a pink color and pink fluorescence due to the formation of a complex MCa-IQ- $\mathbf{C o}^{2+}$ between MCa-IQ and the $\mathrm{Co}^{2+}$ cation. In the presence of metal cations other than $\mathrm{Co}^{2+}$ cation, the pink color becomes pale. The solution is colorless in the presence of the $\mathrm{In}^{3+}$ cation. Figure $5 \mathrm{~d}$ shows pink fluorescence with no metal cation and with the addition of $\mathrm{Co}^{2+}$ cation. In the presence of other metal cations other than $\mathrm{Co}^{2+}$ cation, the fluorescence is weaker. The fluorescence is strongly quenched in the presence of $\mathrm{In}^{3+}$ cation. As shown in Figure 5e, stronger absorption at $540 \mathrm{~nm}$ and similar fluorescence intensity at $640 \mathrm{~nm}$ are observed with the $\mathrm{Co}^{2+}$ cation, compared to when no metal cation is added. In the presence of metal cations other than the $\mathrm{Co}^{2+}$ cation, the absorption at $540 \mathrm{~nm}$ and the fluorescence at $640 \mathrm{~nm}$ is weaker. Figure $5 \mathrm{f}$ shows that the existence of other competing ions, except the $\mathrm{In}^{3+}$ cation, does not disturb the selective detection of the $\mathrm{Co}^{2+}$ cation.
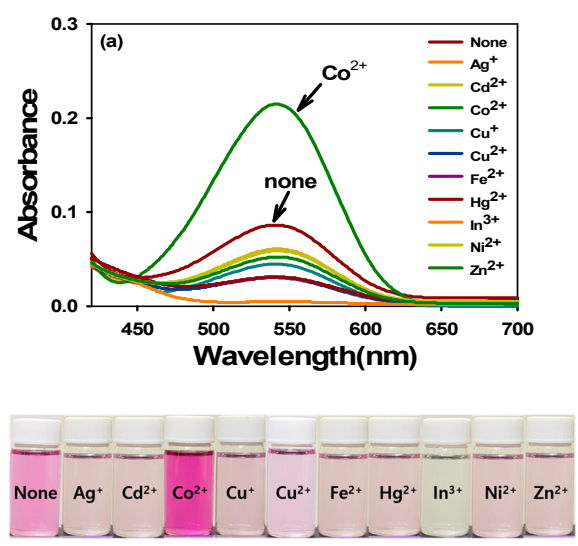

(c)

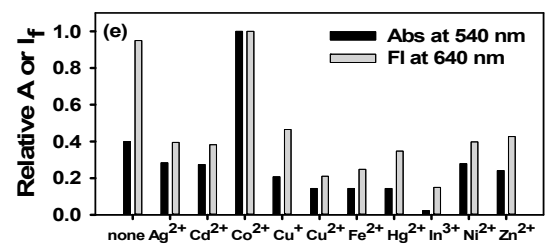

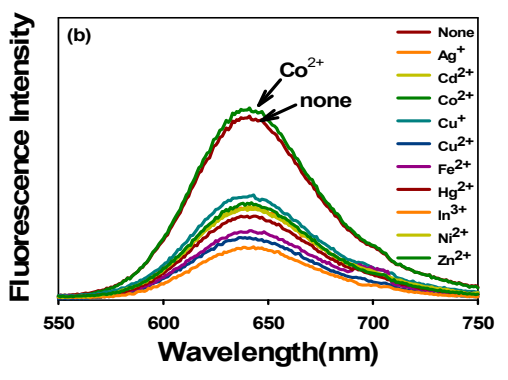

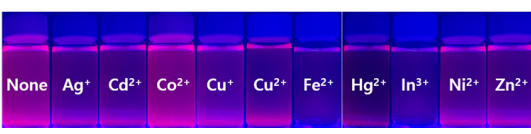

(d)

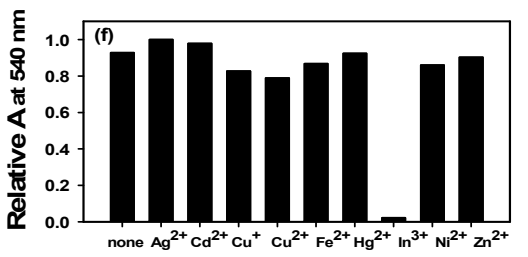

Figure 5. (a) Absorption spectra, (b) fluorescence spectra, (c) photograph of visual color change, (d) photograph of fluorescence change, and (e) relative absorbance and fluorescence intensity of SP-IQ after $350 \mathrm{~nm}$ UV irradiation for $7 \mathrm{~min}$ with the addition of various metal cations; and (f) relative absorbance of SP-IQ after $350 \mathrm{~nm}$ UV irradiation for $7 \mathrm{~min}$ with the addition of various metal cations $\left(1 \times 10^{-4} \mathrm{M} ; \mathrm{Ag}^{2+}, \mathrm{Cd}^{2+}, \mathrm{Cu}^{+}, \mathrm{Cu}^{2+}, \mathrm{Fe}^{2+}, \mathrm{Hg}^{2+}, \mathrm{In}^{3+}, \mathrm{Ni}^{2+}, \mathrm{Zn}^{2+}\right)$ in the presence of $\mathrm{Co}^{2+}\left(1 \times 10^{-4} \mathrm{M}\right)$. 
The Job plot indicates the formation of a 1:1 complex between SP-IQ and the $\mathrm{Co}^{2+}$ cation (Figure 6).

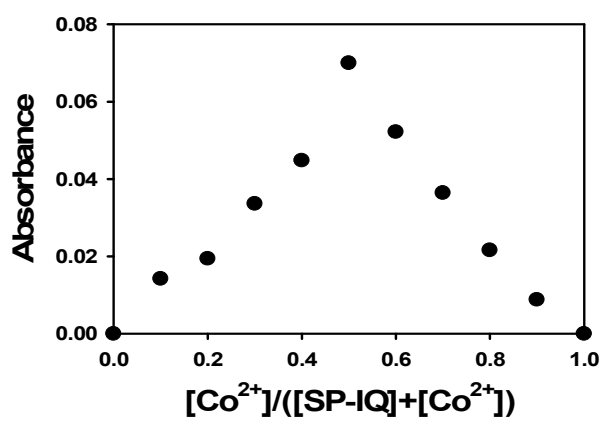

Figure 6. Job plot of SP-IQ and $\mathrm{Co}^{2+}$ cation. Absorbance at $540 \mathrm{~nm}$ for the mixed solutions of SP-IQ and $\mathrm{Co}^{2+}$ cation after $350 \mathrm{~nm}$ UV irradiation for $7 \mathrm{~min}$ was plotted as a function of the molar ratio $\left[\mathrm{Co}^{2+}\right] /\left([\mathrm{SP}-\mathrm{IQ}]+\left[\mathrm{Co}^{2+}\right]\right)$. The total concentration for the mixed solutions of SP-IQ and the $\mathrm{Co}^{2+}$ cation was $1 \times 10^{-5} \mathrm{M}$.

Figure 7 shows the absorption and fluorescence spectra of SP-IQ after $350 \mathrm{~nm}$ UV irradiation for $7 \mathrm{~min}$ with the various concentrations of $\mathrm{Co}^{2+}$ cations. MC-IQ formed by $350 \mathrm{~nm}$ UV irradiation for 7 min produces $\mathbf{M C a}-I_{Q}-\mathbf{C o}^{2+}$ complex with the $\mathrm{Co}^{2+}$ cation. As the concentration of $\mathrm{Co}^{2+}$ increases, more MCa-IQ-Co ${ }^{2+}$ complex are formed and the absorbance at $540 \mathrm{~nm}$ linearly increases up to two-fold. However, the fluorescence intensity at $640 \mathrm{~nm}$ does not change significantly even when the concentration of $\mathrm{Co}^{2+}$ increases. It is thought that the fluorescence efficiency of $\mathbf{M C a}-\mathrm{IQ}_{\mathbf{Q}}-\mathrm{Co}^{2+}$ complexes are similar with that of MC-IQ.
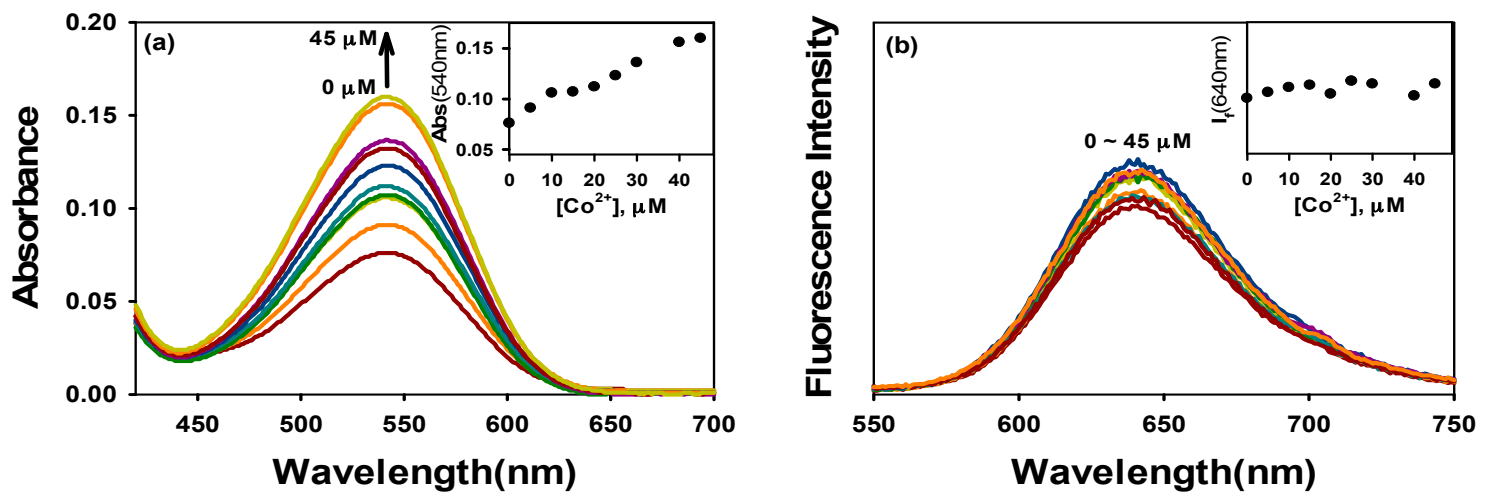

Figure 7. (a) Absorption and (b) fluorescence spectra of SP-IQ after $350 \mathrm{~nm}$ UV irradiation for $7 \mathrm{~min}$ with the various concentration of $\mathrm{Co}^{2+}\left(0 \sim 45 \mu \mathrm{M}\right.$, Different color lines represent different $\mathrm{Co}^{2+}$ concentrations.). Inset: Plots of (a) absorbance at $540 \mathrm{~nm}$ and (b) fluorescence intensity at $640 \mathrm{~nm}$ vs. $\left[\mathrm{Co}^{2+}\right]$.

\subsection{Effect of Other Metal Cations Except $\mathrm{Co}^{2+}$-in the Case of $\mathrm{Fe}^{2+}$}

To investigate the changes in absorption and fluorescence in the presence of other metal cations except $\mathrm{Co}^{2+}$, we chose the $\mathrm{Fe}^{2+}$ cation arbitrarily among the cations. The absorption and fluorescence spectra of SP-IQ after $350 \mathrm{~nm}$ UV irradiation for $7 \mathrm{~min}$ with various concentration of $\mathrm{Fe}^{2+}$ are shown in Figure 8. Both absorption at $540 \mathrm{~nm}$ and fluorescence at $640 \mathrm{~nm}$ are weakened with the increased concentration of $\mathrm{Fe}^{2+}$, in contrast that these are enhanced with the increased concentration of $\mathrm{Co}^{2+}$. The addition of $\mathrm{Fe}^{2+}$ and other metal cations except $\mathrm{Co}^{2+}$ is presumed to inhibit the photoconversion from SP-IQ to MC-IQ by UV irradiation.

This result shows that the $\mathrm{Co}^{2+}$ cation can be selectively detected among the cations. 

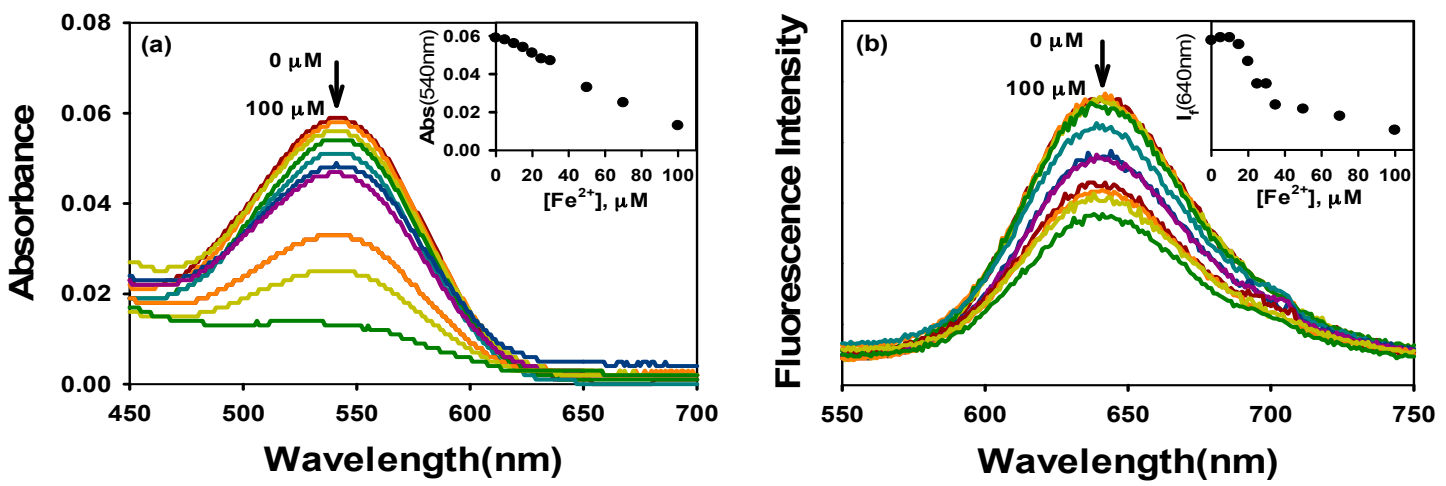

Figure 8. (a) Absorption and (b) fluorescence spectra of SP-IQ after $350 \mathrm{~nm}$ UV irradiation for 7 min with various concentration of $\mathrm{Fe}^{2+}\left(0 \sim 100 \mu \mathrm{M}\right.$, Different color lines represent different $\mathrm{Fe}^{2+}$ concentrations.). Inset: Plots of (a) absorbance at $540 \mathrm{~nm}$ and (b) fluorescence intensity at $640 \mathrm{~nm}$ vs. $\left[\mathrm{Fe}^{2+}\right]$.

\subsection{Selective Sensing of $\operatorname{In}^{3+}$}

Absorption and fluorescence spectral changes and visual color and fluorescence of SP-IQ after being placed in the dark for $7 \mathrm{~h}$ with various metal cations are shown in Figure 9.
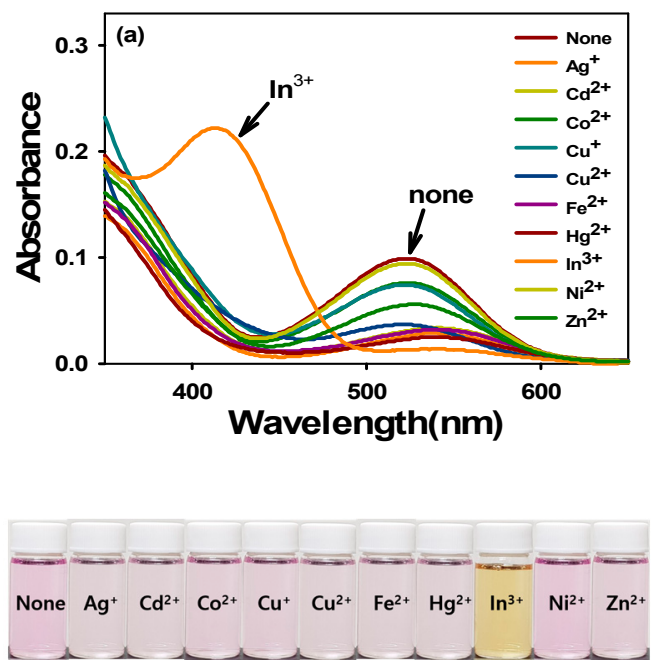

(c)

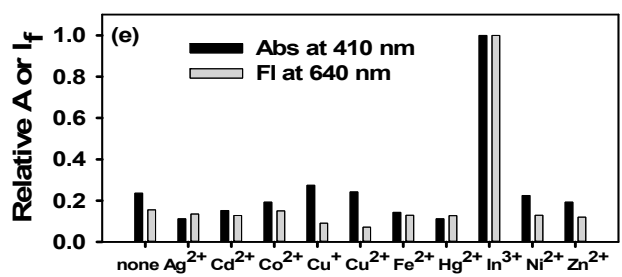

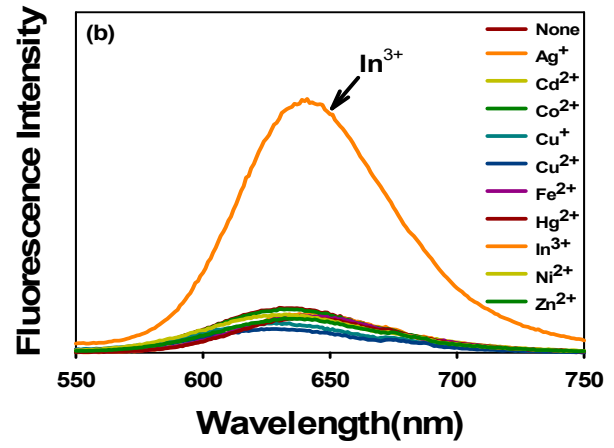

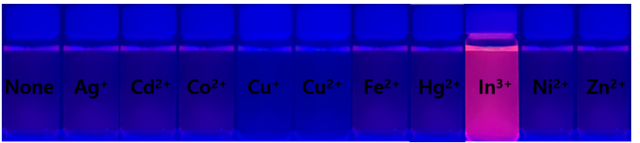

(d)

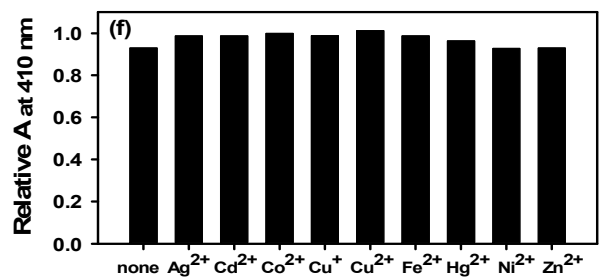

Figure 9. (a) Absorption spectra, (b) fluorescence spectra, (c) photograph of visual color change, (d) photograph of fluorescence change, and (e) relative absorbance and fluorescence intensity of SP-IQ after placed in the dark for $7 \mathrm{~h}$ with the absence and the presence of various metal cations; and (f) relative absorbance of SP-IQ after being placed in the dark for $7 \mathrm{~h}$ with the absence and the presence of various metal cations $\left(1 \times 10^{-4} \mathrm{M} ; \mathrm{Ag}^{2+}, \mathrm{Cd}^{2+}, \mathrm{Co}^{2+}, \mathrm{Cu}^{+}, \mathrm{Cu}^{2+}, \mathrm{Fe}^{2+}, \mathrm{Hg}^{2+}, \mathrm{In}^{3+}, \mathrm{Ni}^{2+}, \mathrm{Zn}^{2+}\right)$ in the presence of $\operatorname{In}^{3+}\left(1 \times 10^{-4} \mathrm{M}\right)$. 
New intense absorption at $410 \mathrm{~nm}$ and a 6.4-fold increase in fluorescence at $640 \mathrm{~nm}$ are observed only with $\mathrm{In}^{3+}$ (Figure 9a,b,e). In the presence of other metal cations except $\mathrm{In}^{3+}$, no absorption band at $410 \mathrm{~nm}$ and extremely weak fluorescence at $640 \mathrm{~nm}$ are observed. Figure $9 \mathrm{c}$ shows the yellow solution with the addition of $\mathrm{In}^{3+}$ cation, and the colorless or pale pink solutions in the presence of metal cations other than the $\mathrm{In}^{3+}$ cation. It was reported that a similar yellow solution of spiropyran derivatives was observed in the presence of $\mathrm{H}^{+}$or $\mathrm{CN}^{-}[14,18]$. Figure $9 \mathrm{~d}$ shows intense pink fluorescence only with the addition of the $\mathrm{In}^{3+}$ cation, while no fluorescence is observed in the presence of other metal cations other than $\mathrm{In}^{3+}$. In the dark, upon the addition of the $\mathrm{In}^{3+}$ cation, the colorless solution of SP-IQ changes slowly to the yellow complex MCb-IQ- $\mathbf{I n}^{3+}$ between $\mathbf{M C b}-\mathbf{I Q}$ and $\mathrm{In}^{3+}$ cation. Figure $9 \mathrm{f}$ shows that the existence of other competing ions does not disturb the selective detection of $\mathrm{In}^{3+}$ cation. Selective detection of the $\mathrm{In}^{3+}$ cation could be possible with SP-IQ by both absorption and fluorescence spectroscopy or with the naked eye.

The Job plot indicates the formation of a 1:1 complex between SP-IQ and $\operatorname{In}^{3+}$ cation (Figure 10).

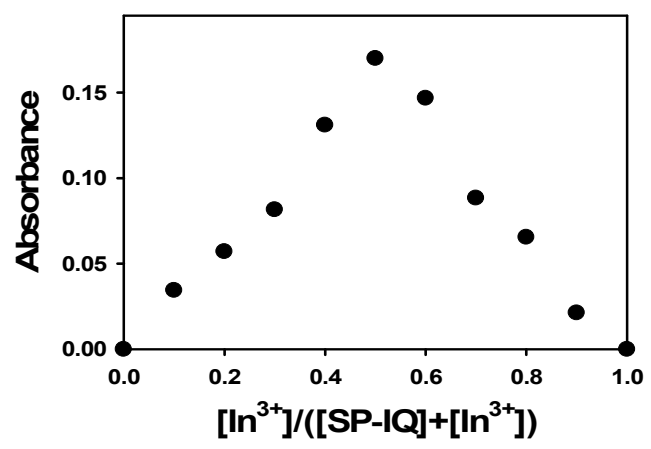

Figure 10. Job plot of SP-IQ and $\mathrm{In}^{3+}$ cation. Absorbance at $410 \mathrm{~nm}$ for the mixed solutions of SP-IQ and $\mathrm{In}^{3+}$ cation after being placed in the dark for $7 \mathrm{~h}$ was a function of the plotted as molar ratio $\left[\mathrm{In}^{3+}\right] /\left([\mathrm{SP}-\mathrm{IQ}]+\left[\mathrm{In}^{3+}\right]\right)$. The total concentration for the mixed solutions of SP-IQ and $\mathrm{In}^{3+}$ cation was $1 \times 10^{-5} \mathrm{M}$.

Figure 11 shows the absorption and fluorescence spectra of SP-IQ after placed in the dark for $7 \mathrm{~h}$ with various concentrations of $\mathrm{In}^{3+}$ cations. As the concentration of $\mathrm{In}^{3+}$ increases, MC-IQ formed in the dark converts to $\mathbf{M C b}-\mathbf{I Q}-\mathbf{I n}^{3+}$ complex with $\mathrm{In}^{3+}$ cation. Absorption at $540 \mathrm{~nm}$, corresponding to MC-IQ decreases, and absorption at $410 \mathrm{~nm}$, corresponding to the MCb-IQ- $\mathbf{I n}^{3+}$ complex increases linearly with the increase in concentration of $\mathrm{In}^{3+}$. An isosbestic point at $483 \mathrm{~nm}$ is clearly observed. Fluorescence intensity at $640 \mathrm{~nm}$ increases linearly as the concentration of $\mathrm{In}^{3+}$ increases, due to the formation of MCb-IQ-In ${ }^{3+}$ complex with higher fluorescence efficiency than MC-IQ.
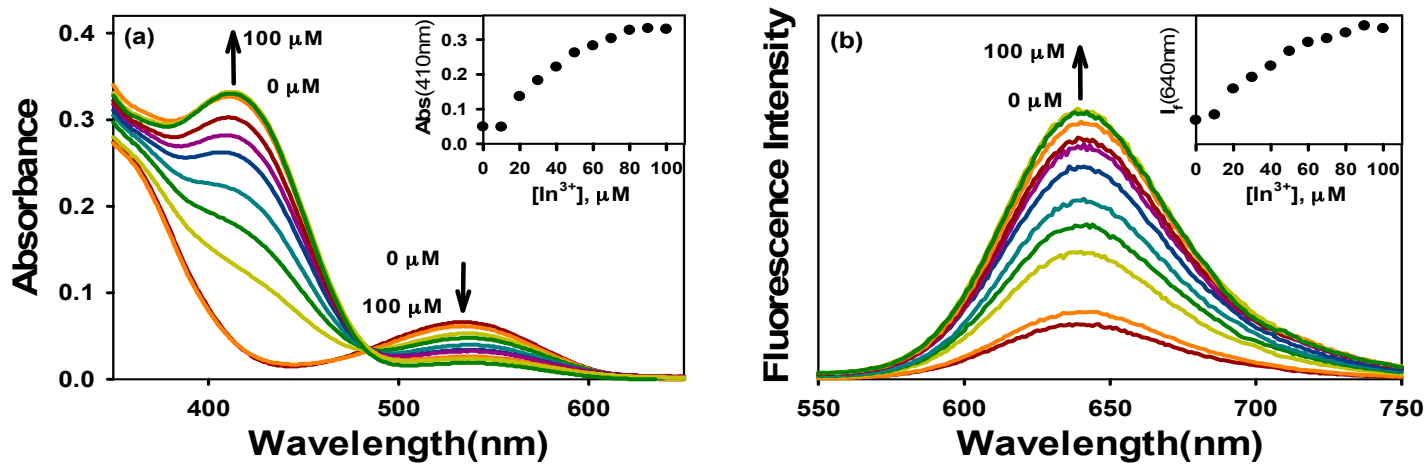

Figure 11. (a) Absorption and (b) fluorescence spectra of SP-IQ after placed in the dark for $7 \mathrm{~h}$ with the addition of $\mathrm{In}^{3+}\left(0-100 \mu \mathrm{M}\right.$, Different color lines represent different $\operatorname{In}^{3+}$ concentrations.). Inset: Plots of (a) absorbance at $410 \mathrm{~nm}$ and (b) fluorescence intensity at $640 \mathrm{~nm}$ vs. [ $\left.\mathrm{In}^{3+}\right]$. 
The $\mathrm{In}^{3+}$ cation could be detected selectively with UV irradiation of SP-IQ using absorption and fluorescence spectroscopy in the range of $10-80 \mu \mathrm{M}$. The linear detection range of the $\mathrm{In}^{3+}$ cation is $10-80 \mu \mathrm{M}$ and the detection limit of the $\mathrm{In}^{3+}$ cation is $10 \mu \mathrm{M}$.

Chemosensors for the independent detection of $\mathrm{Co}^{2+}$ and $\mathrm{In}^{3+}$ cations have been previously reported. However, chemosensors for simultaneous detection of $\mathrm{Co}^{2+}$ and $\mathrm{In}^{3+}$ cations have not been reported until now (see Table 1). To the best of our knowledge, this is the first report of a dual chemosensor for $\mathrm{Co}^{2+}$ and $\mathrm{In}^{3+}$ cations.

Table 1. Chemosensors for $\mathrm{Co}^{2+}$ and $\mathrm{In}^{3+}$ cations.

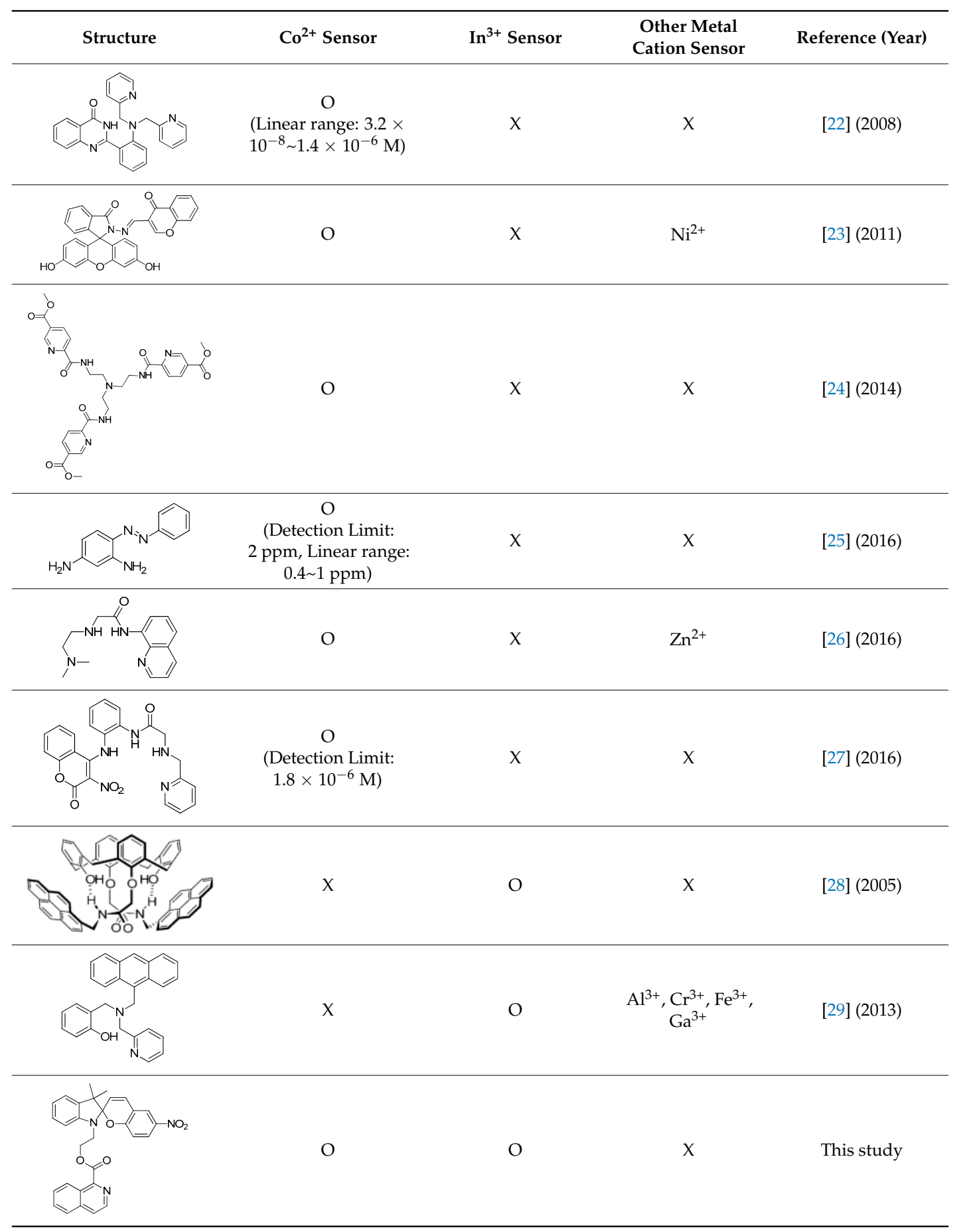




\section{5. $p H$ Effect}

The effect of $\mathrm{pH}$ on the absorption response of the MCa-IQ-Co ${ }^{2+}$ complex and the MCb-IQ-In ${ }^{3+}$ complex was investigated in the $\mathrm{pH}$ range of 1-11 (Figure 12). The characteristic absorptions of the MCa-IQ- $\mathbf{C o}^{2+}$ complex and the $\mathbf{M C b}-\mathrm{IQ}_{\mathbf{2}} \mathbf{I n}^{3+}$ complex are stable between $\mathrm{pH} 3$ and $\mathrm{pH}$ 9. Therefore, $\mathrm{Co}^{2+}$ and $\mathrm{In}^{3+}$ cations could be detected with the naked eye or UV-Vis absorption measurements using the SP-IQ chemosensor over a wide $\mathrm{pH}$ range of 3-9.
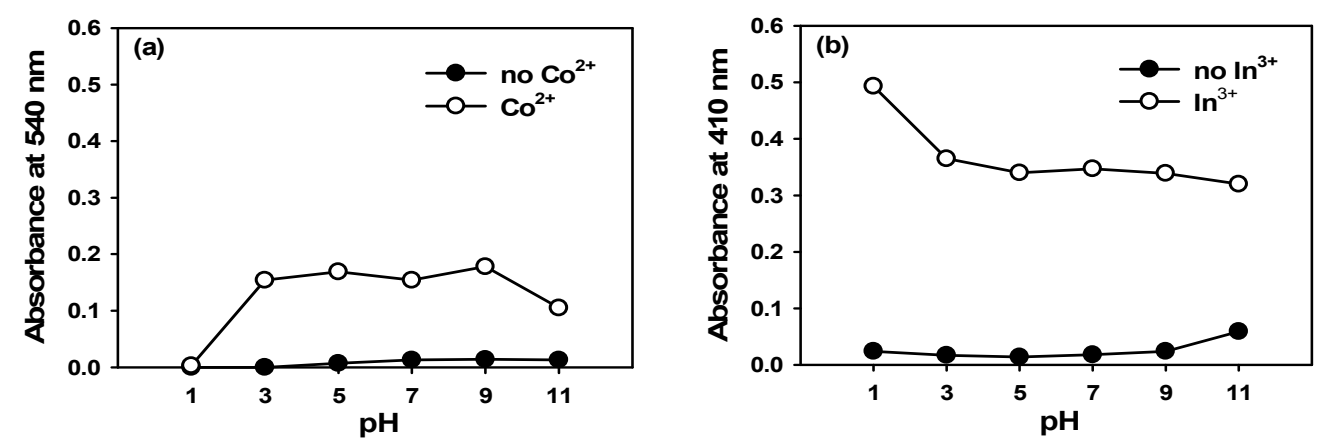

Figure 12. (a) Absorbance at $540 \mathrm{~nm}$ for MCa-IQ-Co ${ }^{2+}$ complex and (b) absorbance at $410 \mathrm{~nm}$ for MCb-IQ-In ${ }^{3+}$ complex at different $\mathrm{pH}(1-11)$.

\section{Materials and Methods}

\subsection{General}

The reagents were purchased from Sigma-Aldrich (St. Louis, MO, USA). ${ }^{1} \mathrm{H}$ - and ${ }^{13} \mathrm{C}-\mathrm{NMR}$ spectra were recorded in $\mathrm{CDCl}_{3}$ at 400 and $101 \mathrm{MHz}$, respectively, using an Inova 500 spectrometer (Varian, Palo Alto, CA, USA). UV-Vis absorption spectra were measured using a quartz cuvette in a UV-2401PC spectrophotometer (Shimadzu, Kyoto, Japan). Fluorescence spectra were measured on an AMINCO-Bowman Series 2 spectrofluorometer (Silver Spring, MD, USA). Unless otherwise noted,

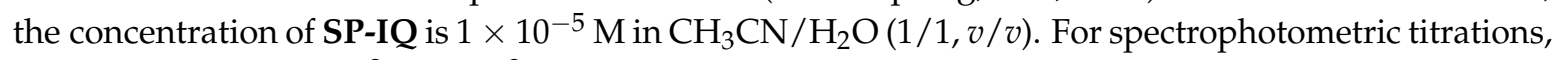
the concentration of $\mathrm{Co}^{2+}$ and $\mathrm{In}^{3+}$ are used in the range of $0 \sim 45 \mu \mathrm{M}$ and $0-100 \mu \mathrm{M}$, respectively.

\subsection{Synthesis of $S P-I Q$}

SP-IQ, a spiropyran derivative appended with isoquinoline, was prepared by the reaction between SP-OH and isoquinoline-1-carboxylic acid (Scheme 3). SP-OH was prepared following the reported procedure [14].

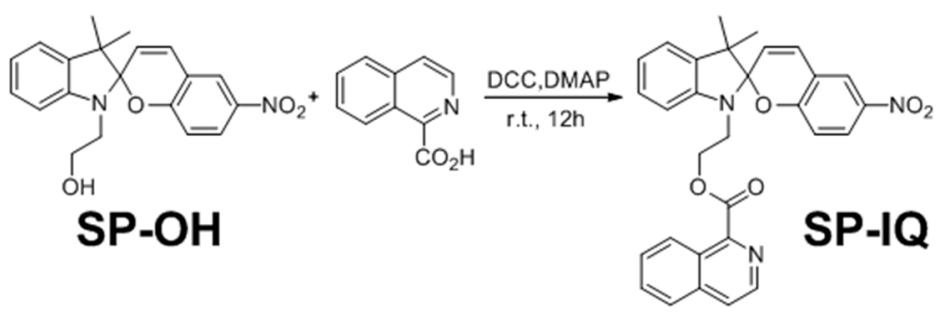

Scheme 3. Synthesis of SP-IQ.

To the mixture of SP-OH (100 $\mathrm{mg}, 0.28 \mathrm{mmol})$ and isoquinoline-1-carboxylic acid (54 mg, $0.31 \mathrm{mmol}$ ) in dichloromethane, dicyclohexylcarbodiimide (58 $\mathrm{mg}, 0.28 \mathrm{mmol}$ ), and 4-dimethylaminopyridine $\left(34 \mathrm{mg}, 0.28 \mathrm{mmol}\right.$ ) were added at $0{ }^{\circ} \mathrm{C}$. The solution temperature was raised to room temperature and the mixture was stirred for $12 \mathrm{~h}$ at room temperature. The reaction mixture was washed with aqueous sodium carbonate solution. The organic layer was dried over anhydrous 
magnesium sulfate and evaporated. The residual mixture was purified with silica gel chromatography (eluent: ethyl acetate $/$ hexane $=1 / 1, v / v)$. Pure SP-IQ $(100 \mathrm{mg}, 70 \%$ yield $)$ was obtained as a light yellow solid.

2-(3', 3'-dimethyl-6-nitrospiro[chromene-2, 2'-indolin]-1'-yl)ethyl isoquinoline-1-carboxylate (SP-IQ). ${ }^{1} \mathrm{H}-\mathrm{NMR}$ $\left(400 \mathrm{MHz}, \mathrm{CDCl}_{3}\right) . \delta 1.26\left(\mathrm{~s}, 3 \mathrm{H},-\mathrm{CH}_{3}\right), 1.27\left(\mathrm{~s}, 3 \mathrm{H},-\mathrm{CH}_{3}\right), 3.68\left(\mathrm{~m}, 1 \mathrm{H},-\mathrm{NCH}_{2} \mathrm{CH}_{2} \mathrm{O}-\right), 3.78(\mathrm{~m}, 1 \mathrm{H}$, $\left.-\mathrm{NCH}_{2} \mathrm{CH}_{2} \mathrm{O}-\right), 4.66\left(\mathrm{t}, 2 \mathrm{H}, J=4.0 \mathrm{~Hz},-\mathrm{NCH}_{2} \mathrm{CH}_{2} \mathrm{O}-\right), 5.99(\mathrm{~d}, 1 \mathrm{H}, J=10.4 \mathrm{~Hz}$, pyran $-\mathrm{CH}=\mathrm{CHPh}-)$, $6.68\left(\mathrm{~d}, 1 \mathrm{H}, J=8.8 \mathrm{~Hz}, \mathrm{NO}_{2}-\mathrm{Ph}\right.$ meta- $\left.H\right), 6.78(\mathrm{~d}, 1 \mathrm{H}, J=7.6 \mathrm{~Hz}$, phenyl $H$ of indoline $), 6.82(\mathrm{~d}, 1 \mathrm{H}$, $J=10.4 \mathrm{~Hz}$, pyran $-\mathrm{CH}=\mathrm{CHPh}-), 6.89(\mathrm{t}, 1 \mathrm{H}, J=7.2 \mathrm{~Hz}$, phenyl $\mathrm{H}$ of indoline), $7.09(\mathrm{dd}, 1 \mathrm{H}, J=1.2 \&$ $7.6 \mathrm{~Hz}$, phenyl $\mathrm{H}$ of indoline), $7.19(\mathrm{dt} 1 \mathrm{H}, J=1.2 \& 7.6 \mathrm{~Hz}$, phenyl $\mathrm{H}$ of indoline), $7.64(\mathrm{dt}, 1 \mathrm{H}, J=1.2$ \& $8.4 \mathrm{~Hz}$, phenyl $H$ of isoquinoline), $7.74(\mathrm{dt}, 1 \mathrm{H}, J=1.2 \& 8.4 \mathrm{~Hz}$, phenyl $H$ of isoquinoline), $7.82(\mathrm{~d}$, $1 \mathrm{H}, J=5.4 \mathrm{~Hz}$, pyridyl meta- $\mathrm{H}$ of isoquinoline), $7.84\left(\mathrm{~s}, 1 \mathrm{H}, \mathrm{NO}_{2}-\mathrm{Ph}\right.$ ortho- $\left.H\right), 7.85(\mathrm{~d}, 1 \mathrm{H}, J=8.8 \mathrm{~Hz}$, $\mathrm{NO}_{2}-\mathrm{Ph}$ ortho- $\left.H\right), 7.88(\mathrm{~d}, 1 \mathrm{H}, J=8.4 \mathrm{~Hz}$, phenyl $\mathrm{H}$ of isoquinoline), $8.59(\mathrm{~d}, 1 \mathrm{H}, J=5.4 \mathrm{~Hz}$, pyridyl ortho- $H$ of isoquinoline), $8.69\left(\mathrm{~d}, 1 \mathrm{H}, J=8.4 \mathrm{~Hz}\right.$, phenyl $\mathrm{H}$ of isoquinoline). ${ }^{13} \mathrm{C}-\mathrm{NMR}\left(101 \mathrm{MHz}, \mathrm{CDCl}_{3}\right)$. $\delta$ 20.0, 26.0, 42.5, 53.1, 63.6, 106.7, 106.9, 115.6, 118.6, 120.1, 122.0, 122.1, 122.7, 124.5, 125.9, 126.4, 126.9, $127.3,128.1,128.6,128.9,130.8,136.0,137.0,141.1,141.7,146.6,148.3,159.5,165.8$.

\section{Conclusions}

In summary, the results of the photoinduced interaction between SP-IQ and various metal cations are as follows:

Upon UV irradiation, colorless and non-fluorescent SP-IQ turns to MC-IQ with a pink color, with absorption at $540 \mathrm{~nm}$ and fluorescence at $640 \mathrm{~nm}$. Even in the dark, SP-IQ converts to MC-IQ. In other words, MC-IQ is formed from SP-IQ by standing in the dark or by UV irradiation. MC-IQ returns to SP-IQ under room light, i.e., visible light. It is thought that the major isomer under visible light is SP-IQ, while the major isomer under UV light or in the dark is MC-IQ.

Absorption and fluorescence spectra of SP-IQ show no changes with the addition of various metal cations. When UV light is irradiated in the presence of various metal cations, colorless SP-IQ forms a pink MCa-IQ-Co ${ }^{2+}$ complex only with the $\mathrm{Co}^{2+}$ cation, which has strong absorption at $540 \mathrm{~nm}$ and fluorescence at $640 \mathrm{~nm}$. With other metal cations, absorption at $540 \mathrm{~nm}$ and fluorescence at $640 \mathrm{~nm}$ are attenuated. In the dark with the addition of various metal cations, SP-IQ shows strong absorption at $410 \mathrm{~nm}$ and strong fluorescence at $640 \mathrm{~nm}$ only with $\mathrm{In}^{3+}$ cation, due to the formation of the MCb-IQ-In ${ }^{3+}$ complex with a yellow color and strong pink fluorescence. From the changes in absorption and fluorescence spectra, it could be roughly deduced that a thermal ring-opening reaction in the ground state favors the zwitterionic structure, which forms the complex with the $\mathrm{Co}^{2+}$ cation, whereas the photochemical ring-opening reaction in the excited state favors the quinonoid structure, which forms the complex with the $\mathrm{In}^{3+}$ cation $[12,13]$.

The results show that SP-IQ acts as a dual sensor for both $\mathrm{Co}^{2+}$ and $\mathrm{In}^{3+}$ cations. SP-IQ could selectively detect $\mathrm{Co}^{2+}$ with UV irradiation and $\mathrm{In}^{3+}$ cations in the dark, by using absorption and fluorescence spectroscopy or by the naked eye.

Acknowledgments: This paper was supported by Sunchon National University Research Fund in 2016.

Author Contributions: Yong-Min Kho performed all experiments including synthesis, purification, and spectroscopic measurements. Eun Ju Shin designed the experiments, analyzed the data, and wrote the paper.

Conflicts of Interest: The authors declare no conflict of interest.

\section{References}

1. Emsley, J. Nature's Building Blocks: An A-Z Guide to the Elements, 2nd ed.; Oxford University Press: New York, NY, USA, 2011; pp. 138-142, ISBN 0199605637.

2. Donaldson, J.D.; Beyersmann, D. Cobalt and cobalt compounds. In Ullmann's Encyclopedia of Industrial Chemistry; Welch, V.A., Fallon, K.J., Gelbke, H.P., Eds.; Wiley-VCH: Weinheim, Germany, 2005; ISBN 9783527306732. 
3. Zywiel, M.G.; Cherian, J.J.; Banerjee, S.; Cheung, A.C.; Wong, F.; Butany, J.; Gilbert, C.; Overgaard, C.; Syed, K.; Jacobs, J.J.; et al. Systemic cobalt toxicity from total hip arthroplasties. Bone Jt. J. 2016, 98, 14-20. [CrossRef] [PubMed]

4. Periodic Table-Indium. Available online: http://www.rsc.org/periodic-table/element/49/indium (accessed on 20 July 2017).

5. Mineral Information: Indium-United States Geological Survey. Available online: https://minerals.usgs. gov/minerals/pubs/commodity/indium/ (accessed on 11 September 2017).

6. Nordberg, G.F.; Fowler, B.A.; Nordberg, M. Handbook on the Toxicology of Metals, 4th ed.; Academic Press: New York, NY, USA, 2014; p. 845, ISBN 978-0-444-59453-2.

7. Gunnlaugsson, T.; Glynn, M.; Tocci, G.M.; Kruger, P.E.; Pfeffer, F.M. Anion recognition and sensing in organic and aqueous media using luminescent and colorimetric sensors. Coord. Chem. Rev. 2006, 250, 3094-3117. [CrossRef]

8. Quang, D.T.; Kim, J.S. Fluoro-and chromogenic chemodosimeters for heavy metal ion detection in solution and biospecimens. Chem. Rev. 2010, 110, 6280-6301. [CrossRef] [PubMed]

9. Zhang, J.; Zou, Q.; Tian, H. Photochromic materials: More than meets the eye. Adv. Mater. 2013, 25, 378-399. [CrossRef] [PubMed]

10. Klajn, R. Spiropyran-based dynamic materials. Chem. Soc. Rev. 2014, 43, 148-184. [CrossRef] [PubMed]

11. Minkin, V.I. Photo-, thermo-, solvato-, and electrochromic spiroheterocyclic compounds. Chem. Rev. 2004, 104, 2751-2776. [CrossRef] [PubMed]

12. Garcia, A.A.; Cherian, S.; Park, J.; Gust, D.; Jahnke, F.; Rosario, R. Photon-Controlled Phase Partitioning of Spiropyrans. J. Phys. Chem. A 2000, 104, 6103-6107. [CrossRef]

13. Guo, Z.-Q.; Chen, W.-Q.; Duan, X.-M. Highly selective visual detection of Cu(II) utilizing intramolecular hydrogen bond-stabilized merocyanine in aqueous buffer solution. Org. Lett. 2010, 12, 2202-2205. [CrossRef] [PubMed]

14. Raymo, F.M.; Giordani, S. Signal processing at the molecular level. J. Am. Chem. Soc. 2001, 123, 4651-4652. [CrossRef] [PubMed]

15. Natali, M.; Soldi, L.; Giordani, S. A photoswitchable Zn(II) selective spiropyran-based sensor. Tetrahedron 2010, 66, 7612-7617. [CrossRef]

16. Shao, N.; Jin, J.Y.; Wang, H.; Zhang, Y.; Yang, R.H.; Chan, W.H. Tunable photochromism of spirobenzopyran via selective metal ion coordination: An efficient visual and ratioing fluorescent probe for divalent copper ion. Anal. Chem. 2008, 80, 3466-3475. [CrossRef] [PubMed]

17. Hur, D.Y.; Shin, E.J. Solvatochromic and photochromic behavior of spiropyran-cored PAMAM dendron and $\mathrm{Cu}(\mathrm{II})$ selective sensing. Bull. Korean Chem. Soc. 2015, 36, 104-110. [CrossRef]

18. Hur, D.Y.; Shin, E.J. A fluorescent chemosensor for $\mathrm{Al}^{3+}, \mathrm{HSO}_{3}{ }^{-}$, and $\mathrm{CN}^{-}$based on a dyad bearing rhodamine and spiropyran units. Bull. Korean Chem. Soc. 2015, 36, 2027-2033. [CrossRef]

19. Liu, J.; Qian, Y. A novel pyridylvinyl naphthalimide-rhodamine dye: Synthesis, naked-eye visible and ratiometric chemodosimeter for $\mathrm{Hg}^{2+} / \mathrm{Fe}^{3+}$. J. Lumin. 2017, 187, 33-39. [CrossRef]

20. Gu, C.; Huang, N.; Gao, J.; Xu, F.; Xu, Y.; Jiang, D. Controlled synthesis of conjugated microporous polymer films: Versatile platforms for highly sensitive and label-free chemo- and biosensing. Angew. Chem. Int. Ed. 2014, 53, 4850-4855. [CrossRef] [PubMed]

21. Gu, C.; Huang, N.; Wu, Y.; Xu, H.; Jiang, D. Design of highly photofunctional porous polymer films with controlled thickness and prominent microporosity. Angew. Chem. Int. Ed. 2015, 54, 11540-11544. [CrossRef] [PubMed]

22. Luo, H.-Y.; Zhang, X.-B.; He, C.-L.; Shen, G.-L.; Yu, R.-Q. Synthesis of dipicolylamino substituted quinazoline as chemosensor for cobalt(II) recognition based on excited-state intramolecular proton transfer. Spectrochim. Acta A 2008, 70, 337-342. [CrossRef] [PubMed]

23. Abebe, F.A.; Eribal, C.S.; Ramakrishna, G.; Sinn, E. A 'turn-on' fluorescent sensor for the selective detection of cobalt and nickel ions in aqueous media. Tetrahedron Lett. 2011, 52, 5554-5558. [CrossRef]

24. Zhou, J.-R.; Liu, D.-P.; He, Y.; Kong, X.-J.; Zhang, Z.-M.; Ren, Y.-P.; Long, L.-S.; Huang, R.-B.; Zheng, L.-S. A highly selective colorimetric chemosensor for cobalt(II) ions based on a tripodal amide ligand. Dalton Trans. 2014, 43, 11579-11586. [CrossRef] [PubMed]

25. Kang, S.-M.; Jang, S.-C.; Kim, G.Y.; Lee, C.-S.; Huh, Y.S.; Roh, C. A rapid in situ colorimetric assay for cobalt detection by the naked eye. Sensors 2016, 16, 626. [CrossRef] [PubMed] 
26. Na, Y.J.; Choi, Y.W.; You, G.R.; Kim, C. A novel selective colorimetric chemosensor for cobalt ions in a near perfect aqueous solution. Sens. Actuators B Chem. 2016, 223, 234-240. [CrossRef]

27. Park, G.J.; Lee, J.J.; You, G.R.; Nguyen, L.T.; Noh, I.; Kim, C. A dual chemosensor for $\mathrm{Zn}^{2+}$ and Co $^{2+}$ in aqueous media and living cells: Experimental and theoretical studies. Sens. Actuators B Chem. 2016, 223, 509-519. [CrossRef]

28. Kim, S.K.; Kim, S.H.; Kim, H.J.; Lee, S.H.; Lee, S.W.; Ko, J.; Bartsch, R.A.; Kim, J.S. Indium(III)-induced fluorescent excimer formation and extinction in calix[4]arene-fluoroionophores. Inorg. Chem. 2005, 44, 7866-7875. [CrossRef] [PubMed]

29. Kim, H.; Kim, K.B.; Song, E.J.; Hwang, I.H.; Noh, J.Y.; Kim, P.-G.; Jeong, K.-D.; Kim, C. Turn-on selective fluorescent probe for trivalent cations. Inorg. Chem. Commun. 2013, 36, 72-76. [CrossRef]

Sample Availability: Samples of the compounds are not available from the authors.

(C) 2017 by the authors. Licensee MDPI, Basel, Switzerland. This article is an open access article distributed under the terms and conditions of the Creative Commons Attribution (CC BY) license (http:/ / creativecommons.org/licenses/by/4.0/). 